\title{
Spitting rhymes and changing minds: Global youth work through hip-hop
}

\author{
Eleanor J. Brown* and Laura Louise Nicklin - University of York, UK
}

\begin{abstract}
This article explores the impact of a global youth work project that aimed to engage young people in social issues through the medium of hip-hop. We discuss the literature on education for social justice and then give an overview of the hip-hop project we analysed. We go on to explore the qualitative findings, asking what practices were most successful in engaging 'marginalized' young people and whether the project met its aims in terms of the perceived outcomes for and of the participants. We consider how the project built self-esteem and draw conclusions about the implications of such projects for developing positive attitudes to learning and for consciousness-raising regarding global social issues.
\end{abstract}

Keywords: global youth work, hip-hop, self-esteem and confidence, attitudes to learning, consciousness-raising

\section{Introduction}

Performing arts, including musical expression and spoken word, have been used recurrently in attempts to rehabilitate, motivate and change attitudes among young people (Baker and Homan, 2007). The impact of rap music has been present in discourse surrounding the worldview of young people since the 2000s (Baker and Bor, 2008). However, it focused mainly on a more negative message surrounding issues such as violence, substance abuse, sexuality and gender (Adams and Fuller, 2006). Nevertheless, the potential of this medium to change perceptions is increasingly recognized (Tyson, 2002).

This article draws on data compiled for the evaluation of a global youth work hiphop project conducted by an educational charity. It establishes correlations between participant perceptions of project outcomes and the project aims of providing young people with positive experiences of learning and skills development, thus enhancing self-esteem and reducing risk factors for antisocial behaviour (defined as actions that harm or demonstrate a lack of consideration for the well-being of others (Berger, 2003) or that violate the rights of another person (Calkins and Keane, 2009)). The participants were directed to the project through mechanisms such as the job centre or local colleges. Most participants, at the time of enrolling, were not in education, employment or training (NEET), or were otherwise identified as 'marginalized', due to criminal records or exclusion from mainstream education.

The project aimed to challenge the exclusion implied by labels such as 'marginalized', and value participants' experiences, aiming to engage young people with global and social issues. The male and female participants were from a range of British ethnic backgrounds including white, black and Asian, drawn from the local area, a suburb of a medium-sized UK city. The organization conducting the project was a 
Development Education Centre, specializing in global youth work. Sessions ran over three years, considering issues such as financial independence, political identity and mental health, with an overarching focus on money, power and respect. Activities used creative outputs such as lyric writing, art, interviews and tracks to develop self-esteem. The aim was to develop critical consciousness (Freire, 1972) and provide opportunities for participants to take action and disseminate their ideas to the wider community.

The research objective was to determine how the project met its core aims analysing participant perceptions of their outcomes to explore the extent to which the project generated social engagement, using a critical pedagogy framework. We look for evidence of safe spaces, collaborative dialogue and experiential learning, and consider how participants reflected on their own realities and used their own voices to explore issues of power and social injustice, leading to greater critical consciousness. These were all conceptualized in the context of the project, where for example, dialogue was understood by the openness demonstrated to listening to others' views and responding accordingly. We ask whether participants were encouraged to describe their realities and whether they felt able to challenge and change these.

We argue that hip-hop provided a vehicle to connect young people to social issues and engage them in learning. As such, the project provides an important case study of how to engage 'marginalized' young people and encourage prosocial behaviours, specifically those that engage them with the local community and encourage positive role models. This does not mean necessarily conforming to expected social norms, but rather reflecting on relationships with the wider community.

\section{Connecting literatures}

We draw on a range of literature, exploring projects designed to engage 'marginalized' or 'at risk' young people, then moving to a discussion of critical pedagogy as a way to challenge some of the disadvantage experienced by these young people. This provides a theoretical framework through which we analyse the outcomes of the project. This is compared to the educational approaches used for the project, considering the philosophies of global youth work and the methodology of connect-challenge-change (Williams and Edleston, 2010). Finally, we examine how popular culture, and specifically hip-hop music, can be used as a tool to engage young people, and we consider how and why these formats can be successful in capturing young people's imaginations and developing self-esteem.

\section{Engaging marginalized young people}

In recent years debates around young people as 'disaffected' or 'disengaged' have emerged from academic, political and public sources. The term 'disaffected' in this context can be understood in many ways and manifests itself through a range of behaviours, from lack of social engagement through to disruptive or criminal activities (Newburn et al., 2013; Hanrahan, 2014). However, 'disaffection' is difficult to define and numerous different terms are used to exemplify it (Holroyd and Armour, 2003). Labels such as 'alienated' (Halas, 2002), and 'disenfranchised' (Riley and Rustique-Forrester, 2002) allude to the lack of young people's engagement in society. Other terms like 'oppressed' (Freire, 1972) or 'excluded' (Steer, 2000) create a sense of 'otherness' suggesting that these young people cannot access dominant cultural and social spaces as their contemporaries do. Some labels put more emphasis on society to help young people who are victimized, identifying them as 'at risk' (Goodman, 1999) or 'troubled' (Halas, 2001), while others place more blame on young people themselves, 
regarding them as 'underserved' (Martinek and Hellison, 1997) or 'delinquent' (Sugden and Yiannakis, 1982).

Similarly, there are numerous factors cited as causes of disaffection, including low self-esteem, poverty and unemployment (Holroyd and Armour, 2003). Young people are often considered particularly vulnerable to disaffection, with adolescence seen as a time of greater susceptibility to crises or higher likelihood of experiencing conflict or stress (Nash and Henderson, 2010). Declining involvement in community activity and an ever-greater influence of individualism on modern society are often perceived to exacerbate this problem (Giddens, 1991).

It is often multiple layers of disadvantage that conspire to create circumstances that make it difficult, or perhaps unappealing, for some young people to conform to social expectations. Many have negative experiences of formal education, which some argue is due to schools' role in perpetuating social and economic inequalities (Illich, 1973). This occurs when young people find that their habitus is incoherent with the structures of schooling. For Bourdieu (1990), this was because the ways of being and talking from lower social class backgrounds clash with the dominant models within school, so some students are favoured in their school experience. This concept of habitus describes how our home environments determine our ability to engage in educational settings. Habitus refers to the ensemble of dispositions by which actions and attitudes in the everyday world are habituated, and thus taken for granted - it becomes thoughtless because it becomes embodied (Bourdieu, 1990).

However, we choose to frame young people regarded as 'marginalized' or 'excluded'. The reasons for their disengagement are not straightforward. Informal spaces for learning are seen as potential sites for empowering young people to learn on their own terms, and in an environment that does not reproduce inequalities in the same way as the school system they often feel has failed them. Youth work offers this by operating where the supposed 'disenfranchised' youth are; in their own spaces and communities (Batsleer, 2008). It is often youth work and non-formal education that employ pedagogies that endeavour to connect young people with the issues they face.

\section{Global youth work and critical pedagogy}

Much of the basis for youth work draws on principles of popular education and critical pedagogy, which aims to inform the way we question society (McLaren, 2009). Given that so much of the disillusion experienced by many young people comes from being 'othered' by or 'excluded' from the dominant ideology, empowering the 'oppressed' to critique that ideology can enhance self-esteem. Self-esteem is a complex concept relating to people's perceived confidence in their own ability and what they think about the self (Smith and Mackie, 2007). It relates to how people understand their social environment and can be used as a predictor of certain outcomes, including academic achievement (Marsh, 1990) or criminal behaviour (Orth and Robbins, 2014). Critical pedagogy aims to reveal how our social relations are 'deeply rooted in a nexus of power relations' and encourages us to ask 'how our everyday common-sense understandings - our social constructions or "subjectivities" - get produced and lived out' in an environment where 'some forms of knowledge have more power and legitimacy than others' (McLaren, 2009: 63). This can in turn impact on people's understanding of their own perceived successes or failures. For this reason, many argue that for education to truly empower marginalized young people, it needs to provide opportunities for them to examine power relationships and social injustices (Brookfield, 2000).

Critical pedagogy is an approach that favours education as an active process in which learners participate as equals, rather than the passive learning of being filled 
with information by a teacher or gatekeeper of knowledge, something referred to as 'banking education' (Freire, 1972). Banking education is unlikely to empower learners, since 'the more students work at storing the deposits entrusted to them, the less they develop the critical consciousness that would result from their intervention in the world as transformers of that world' (Freire, 1972: 54). This critical consciousness is defined as 'learning to perceive social, political, and economic contradictions - developing a critical awareness - so that individuals can take action against the oppressive elements of reality' (Freire, 1972: 19). In this way students become empowered subjects achieving 'a deepening awareness of the social realities which shape their lives, discovering their own capacities to recreate them' (Darder et al., 2009: 14). Therefore, it is essential that educational processes should be creative and experiential, taking place in an environment adapted to the context, where participants feel safe and respected.

Building on the approaches of critical pedagogy, global youth work locates itself in young people's everyday experiences and encourages critical analysis of local and global influences on their lives and communities. It aims to raise awareness of inequalities and injustices, build understanding of the connections between their own lives and those of others around the world, and develop active participation (Adams, 2010). The teaching methodology associated with this work is 'connect-challengechange', which aims to connect young people and their like-minded peers to issues that are relevant and important to them. These connections are then developed by encouraging young people to 'challenge themselves to gain a more critical understanding and to challenge inequality and injustice in the world around them' and finally to 'support young people to take action to bring about positive change towards a more just and sustainable world' (Shah, 2010: 3). This can work at a local level, but is primarily conceived as a way of connecting young people to global issues and the ways these interact with their own experiences and opportunities to pass their learning onto others (Brown, 2018).

Pedagogies that aim to facilitate critical thinking use participative methodologies that build on young people's existing knowledge, while allowing them to challenge some of their taken-for-granted assumptions in a safe space (Brown, 2014). This concept of a safe space is important. It needs to be established in a way that allows young people to voice their concerns without risk of judgement and support them when their own deeply held assumptions are challenged (Brown, 2014). There needs to be awareness and openness to a range of different perspectives and an outlet for the young people to express their concerns (Mezirow, 2000).

\section{Hip-hop culture and engagement}

It is important to remember that learning should take place through a lens that participants want to engage with, due to previous negative experiences of education. For many young people, it is through the cultures and habitus in which they are situated that they can explore the complex issues that impact their lives, and potentially challenge injustices. Hip-hop is 'firmly rooted in the local and temporal' (Potter, 1995: 146); it has proven itself useful for youth to navigate local spaces and histories while constructing individual styles and identities. There is a growing literature about the ways in which music and popular culture can generate political engagement (Gracyk, 2001), and restructure negative identities (Cieslik and Pollock, 2002). Eyerman (2002) describes how music can help form collective identities and thus contribute to collective positive action. Music and expression of identity are connected with young people's style, language and personality development (Schwartz and Fouts, 2003). 
Hip-hop is a medium used recurrently for projects aiming to engage disaffected young people, particularly in urban contexts, with significant power attributed to its mass appeal and representative nature as a tool to help them make meaning in their worlds (Campbell et al., 2007). This is particularly significant since the genre was created by and for urban, working-class youth (Kitwana, 2002; Hara, 2012). At the origin of the genre, hip-hop artists were regarded as storytellers disturbing the status quo by sharing uncomfortable truths and representations of real life for ethnically marginalized groups within US society, including political oppression, neglect and stigmatization of black youth as lesser members of society (Hollander and Quinn, 2016). Though rooted in a race-specific context, the influence of this medium for youth culture has also been identified as transcending race, and influencing a diverse range of youth cultures, accessing and challenging elements and practices within these groups, such as living conditions (Hollander and Quinn, 2016), substance abuse (Herd, 2014) and street behaviour, occurrences and codes (Hunnicutt and Andrews, 2009).

Hip-hop and rap music are seen to possess increasing political power (Forman, 2013) and provide opportunities for spreading messages of social change (Abrams, 1995). McDonnell (1992: 89) suggests that the messages of rap music generally fall into two broad categories: 'individualized effort' and 'collective action', which can lead to social change. Nevertheless, there are questions about the extent to which hiphop can be positive in its directive of change, for while it can generate a sense of community it tends to speak of the 'realities of displacement, disillusion, and despair created by the austerity economy of post-industrial capitalism' (Lipsitz, in Keyes, 2004: 6). There are also questions about gender (Stapleton, 1998) and the role of women in rap music, as lyrics are often considered misogynistic (Adams and Fuller, 2006). Indeed, 'rap' music has often been associated with negative behaviours including violence and crime (Miranda and Claes, 2004) and is sometimes considered a subculture that offers glamourized perceptions of antisocial behaviours (Kubrin, 2005).

However, a study by Travis and Bowman (2012: 455) found that 'positive ethnic identity was associated with greater music-influenced empowerment' and that the young people 'least likely to show depressive symptoms were individuals who felt that rap music inspired them to connect with others, consider experiences of others, think critically about the world around them, and want to make a difference to their communities'. Agency is a key aspect of achieving these positive outcomes and refers to 'the ability of individuals to operate, through their own active will, regardless of wider social structures that may otherwise limit the choices that they may possess' (Dedman, 2011: 511). In a large study looking at the ways in which young people engage with hiphop culture both actively and passively, Dedman (2011: 511) claims that subculturalists (defined as those who actively engage in hip-hop culture, writing and making their own music) 'shape their own sense of hip-hop and grime culture in accordance with the notion of agency. They are actively engaged in responding to, and continuously resisting, mainstream images and messages from which they feel disconnection'.

\section{The hip-hop project}

The project brought young people together to discuss issues of money, power and respect predominantly through hip-hop. It aimed to break cycles of exclusion through creative activities developing positive attitudes to learning and transferable skills, and building confidence, thus increasing employability, pro-social behaviours and engagement with social issues. This was done through interactive sessions facilitating dialogue and providing peer mentoring as progression opportunities. The organization 
had studio facilities with recording equipment, and the facilitators were all qualified youth workers, trained in the connect-challenge-change methodology.

The data was compiled through evaluation processes and used project reports, which included interviews, field notes, session plans and feedback collected between 2013 and 2016 from practitioners and participants. Interviews were conducted with 12 young people; six at the end of Year 1 and six at the end of Year 3, reported using pseudonyms. The data therefore provide snapshots of the project at two points in time. Due to changes in the group between Year 1 and 3, and the fact that not all participants attended every week, it was impossible to interview any participants on both occasions.

Table 1: Critical pedagogy, practices and outcomes

\begin{tabular}{|c|c|c|}
\hline $\begin{array}{c}\text { Aspects of critical } \\
\text { pedagogy }\end{array}$ & Practices and pedagogies & Outcomes \\
\hline $\begin{array}{l}\text { Evidence of } \\
\text { constructed safe } \\
\text { spaces }\end{array}$ & $\begin{array}{l}\text { - Informal environment } \\
\text { - Non-judgemental atmosphere } \\
\text { - Facilitated discussion }\end{array}$ & $\begin{array}{l}\text { - Positive attitudes to learning } \\
\text { - Developing community } \\
\text { - Confidence development }\end{array}$ \\
\hline $\begin{array}{l}\text { Evidence of } \\
\text { collaborative dialogue }\end{array}$ & $\begin{array}{l}\text { - Facilitated discussion } \\
\text { - Session inputs } \\
\text { - Peer mentoring } \\
\text { - Working on tracks/outputs together } \\
\text { - Connect-challenge-change } \\
\text { methodology }\end{array}$ & $\begin{array}{l}\text { - Developing understanding } \\
\text { - Reflecting on social issues } \\
\text { - Developing community } \\
\text { - Confidence development }\end{array}$ \\
\hline $\begin{array}{l}\text { Evidence of creative } \\
\text { and experiential } \\
\text { learning }\end{array}$ & $\begin{array}{l}\text { - Working on tracks/outputs together } \\
\text { - Outings and community days } \\
\text { - Connect-challenge-change } \\
\text { methodology } \\
\text { - Lyric writing } \\
\text { - Creative outputs }\end{array}$ & $\begin{array}{l}\text { - Skills development } \\
\text { - Empowering action } \\
\text { - Developing understanding } \\
\text { - Confidence development } \\
\text { - Positive attitudes to learning }\end{array}$ \\
\hline $\begin{array}{l}\text { Evidence of } \\
\text { participants defining } \\
\text { their own realities } \\
\text { and finding their own } \\
\text { voices }\end{array}$ & $\begin{array}{l}\text { - Connect-challenge-change } \\
\text { methodology } \\
\text { - Lyric writing } \\
\text { - Peer mentoring } \\
\text { - Choosing processes } \\
\text { - Posting and disseminating on social } \\
\text { and other media }\end{array}$ & $\begin{array}{l}\text { - Skills development } \\
\text { - Developing understanding } \\
\text { - Empowering action } \\
\text { - Confidence development } \\
\text { - Positive attitudes to learning }\end{array}$ \\
\hline $\begin{array}{l}\text { Evidence of exploring } \\
\text { and acting on issues } \\
\text { of power and social } \\
\text { injustice }\end{array}$ & $\begin{array}{l}\text { - Choosing processes } \\
\text { - Posting and disseminating on social } \\
\text { and other media } \\
\text { - Facilitated discussion } \\
\text { - Session inputs } \\
\text { - Peer mentoring }\end{array}$ & $\begin{array}{l}\text { - Dissemination of outputs } \\
\text { - Empowering action } \\
\text { - Consciousness }\end{array}$ \\
\hline
\end{tabular}

We used self-selecting convenience sampling, drawn from willing participants present on the days of data collection (Wellington, 2015). This meant that it was difficult to present a coherent narrative about participant progression. There are limitations pertaining to the ad hoc nature of the data collection, and the possibility that we were seen as 'outsiders', with participants feeling pressured to report positively (Bryman, 2016). We triangulated the data with thematic analysis of registers and feedback forms, session plans and participant outputs in the form of tracks, podcasts and online media, including Facebook, YouTube and SoundCloud. This allowed some 
recognition of continuity to get an idea of the dissemination and reach of the project, quantifiable through the followers and views of the outputs.

The analysis used the project outcomes and mapped these against participant perceived outcomes, which emerged inductively from the interview data. We used five key aspects of critical pedagogy as an analytical framework and mapped these against the practices and pedagogies used. The interviews and documentation were then used to determine how these contributed to outcomes identified by participants (Table 1).

The project aims formed the starting points for the analysis. We used the participants' voices to determine the extent to which the participants discussed these outcomes through inductive interview analysis and identified practices that facilitated these outcomes. While the content and the session inputs made connections to the global dimension, the young people were free to pick up on the aspects that most resonated with them.

\section{Practices and pedagogies}

\section{Evidence of constructed safe spaces}

An important aspect of the sessions was the informal environment. Young people had freedom to attend as they pleased, engage in activities they were comfortable with and determine the outputs they produced. These ranged from lyric writing to making posters or finding beats for others to add lyrics. The young people were encouraged to identify the issues that related to their own lives in a relaxed and nonjudgemental setting:

you can say what you want and people don't judge you in a harsh way, not like teachers ... Others can be too much in your face but they're really relaxed here. (Samantha)

By providing the young people with a safe space to express themselves, the project inspired and gave them confidence. They could look at ways to overcome their problems and voice their concerns in a register and discourse they felt comfortable using. This empowered them in a way that often formal environments had not, leading to more positive attitudes to learning.

\section{Evidence of collaborative dialogue}

The sessions ran on a weekly basis and addressed a range of issues through the connect-challenge-change, global youth work methodology (Williams and Edleston, 2010). With experienced facilitators asking questions and provoking discussion within the group, the young people began to construct ideas around the themes. Here, facilitators introduced a global dimension, relating experiences to broader issues and how these manifest in different contexts. These provided foundations for working on tracks and other outputs in an environment that fostered collaboration:

The studio itself is just one reason to come, it's a social hub as well and people come here because it's good vibes and I've seen people who've come here just to chill and they've ended up getting involved. (Andrew)

Through facilitated conversations about complexity, participants had opportunities to reflect on global social issues in ways they had not done before. This meant they developed their understanding and gained confidence to voice their opinions. 


\section{Evidence of creative and experiential learning}

Creative and experiential aspects were important features of the sessions, enabling an active role in learning. This was motivating and the focus on creativity stimulated different ways of learning. The majority of the sessions involved lyric writing as an output after the initial discussion, and participants had the opportunity to record their lyrics in the studio facilities. There were examples of collaboration on creative outputs relating to ideas raised in the discussions, such as graffiti, writing and recording musical tracks, radio documentaries and video blogs. Participants worked together and contributed different skills - some sang, while others provided technical know-how, giving rise to collaboration. Participants took ownership of their outputs, developing music-making and presentation and communication skills. Being able to disseminate the outputs, through blogs or social media, was empowering for many participants, adding to their confidence development. In addition, there were allocated days each year that involved experiential learning in the local community. They ran sessions with groups such as Brownies, with local Roma community organizations, and a full-day event in the city centre performing some of their tracks live.

\section{Evidence of participants defining their own realities and finding their own voices}

The importance of participants finding their voices and being able to define their own realities is central to critical pedagogy. The connect-challenge-change methodology facilitated this freedom to choose their own processes and outputs: 'we can bring up anything we really want to and nobody forces you to do anything you don't want to' (Keith).

The online dissemination of blogs and tracks was empowering, creating virtual and physical networks, drawn initially from the young people's own social groups, with a sense that they would return to their communities and discuss issues with friends, sharing the music they had made: 'Here you learn something, you speak about it with friends, you pick up other things off other people then you do something productive out of it too' (Paul).

Many saw the benefit of reaching out to others who listened to the music and felt that there were opportunities to spread positive messages. Each week there was a creative output, such as a track or podcast created as a collaborative effort and then shared with the wider community online. While the sessions were 'a lot more than just music' (Michael) and some said they had 'career lessons and life lessons' (Tariq), the music was a key aspect that facilitated disseminating ideas on various topics. This helped participants to construct their own ideas, developing skills and confidence.

\section{Evidence of exploring and acting on issues of power and social injustice}

With an informal environment and participant-led sessions, facilitators aimed to ensure that the content of social issues was covered. These themes in the session plans were designed to be of interest to the young people and included the following:

- healthcare, mental health, personal well-being

- community diversity

- female empowerment, gender issues, suffragettes

- love, friends, relationships

- financial planning, employment 
- guns, knives, conflict

- inequality

- law enforcement, restorative justice

- drugs, substance abuse

- racial issues, black history month

- youth parliaments, democratic participation

- protest music

- capitalism, socialism, communism

- human rights, child rights

- media power.

Consistent with the global youth work pedagogy, the stimuli and topics were designed to start with interests and issues identified by young people. The content offered participants new perspectives on global issues along with tools to engage in a more critical analysis of the world around them. This opened participants' minds to opportunities, allowing them to appreciate and value the opinions and ideas of those who thought differently.

The stimuli provided by the facilitators included TED talks (e.g. Chimamanda Adichie's Danger of a Single Story), video clips, music tracks, worksheets and handouts, Wikipedia entries and posing provocative questions. This led to facilitated discussion and critical reflection on how the issues impacted on the young people's lives and how they could act to make changes where they perceived injustices. One key way in which they did this was through passing their learning onto others, with 10 young people doing peer mentor training. Another was through disseminating tracks and podcasts they made to a wider group of young people. The weekly updates from the sessions were all uploaded onto the website with 65 entries, with views ranging from 37 to 10,222. The website had a wide reach with several hundred followers on Twitter and Facebook, and subscribers to the YouTube channel and SoundCloud. This fed into confidence development and empowerment, leading to possibilities for critical consciousness. This was recognized by one peer mentor:

They've covered different topics ... through talking about different things they're then going to show at least their friends and that's exposure. So just via that music they're talking about deeper real world issues with their friends and allowing their friends to listen to their points ... through being here ... showing their friends the tunes they would then be forced to realize there's this stuff going on in the world and my friends care about it, the knock on domino effect is good. (Tariq)

\section{Intended and perceived outcomes}

We correlated the intended outcomes with the participant-perceived outcomes that emerged from the inductive analysis of the interview data. The coding revealed four main themes from the participants' responses: peer relationships, positive attitudes to learning, confidence and skill development. A further four themes were also present, but to a lesser extent. These can be seen in Table 1, but are not included at length here. Below, we illustrate the ways the participants' discussed the four main themes and how the project reached these outcomes. 


\section{Peer relationships}

Participants valued the peer support networks and relationships they had developed. Opportunities to share personal stories, feelings and ideas were abundant, and group members engaged with each other on a personal and discursive level. Participants expressed their ability to communicate, trust and engage with other young people as a life alteration that they attributed to the project. Several young people described the nature of being able to share in a trusted group setting as therapeutic, supportive and a place they felt able to speak:

The conversations and lessons here help; they help with everyone in the team. It would only take that one voice to start something up and each person who is shy or scared at the start feels free to open up and share in the group, they feel happy to. They know we're not here to judge and basically support each other. (Keith)

Positive community provision was arguably the strongest and most recurrently reported outcome of this project, as many participants commented that this was a new concept for them. Throughout the project, emphasis was placed on removing judgement and creating a community where fear of ridicule or rejection was overcome. The young people report feeling 'safe', 'free' and 'able to get support' from their peers, acknowledging that they all 'support each other' (Keith).

Developing this community also offered opportunities for confidence development through the personal sharing of experiences, which allowed opportunities for others to gain insights into the issues raised as peers rather than outsiders: 'The discussions help everyone. Even if you haven't been in the situation before you can get a feel for how they feel, how they got into it and how they can get themselves out of it' (Peter).

Some participants attributed the development of a positive peer support network to a life change. For others it was a subtler change - making friends and developing social skills.

\section{Positive attitudes to learning}

Subject matter, style and working atmosphere all contributed to the enjoyment of the sessions. Participants were invited to talk about their own opinions and experiences, as well as facilitator input on the topics. The young people highlighted the importance of a safe and enjoyable environment within which they could discuss issues without fear of repercussion, maintaining a light-hearted approach and positive space through which difficult subject matter could be sensitively explored.

The safe and positive environment also encouraged the development of thinking skills with one participant commenting: 'we're told how to think, not what to think' (Matt). This is one of the ways the delicate balance was managed between ensuring activities were participant-led and the achievement of the intended outcomes. While the organization has a clear value-base, as was sometimes apparent from the stimuli, there was an emphasis on providing a range of perspectives and encouraging participants to think about issues and recognize the global dimension in some cases, rather than having specific outcomes in terms of attitudes to the issues.

This openness to different perspectives was key to maintaining a positive atmosphere. For many, negative experiences of school had deterred them from 'education'. Yet through the sessions, they reported feeling interested and able to learn. Some felt this had given them more direction, and more ideas about what 
they wanted to do. They reported thinking more about 'deep questions' (Rob), using knowledge to make better judgements and becoming open-minded:

If you don't know a lot about a subject then naturally you're going to be a bit narrow-minded towards it, but to be able to speak about it and have a lot of opinions projected, it is mind-opening for a lot of people. It is for me. (Tariq)

Through developing thinking skills, learning to value and acknowledge the opinions of others, and exploring a range of topics, the young people demonstrated their interest and enjoyment in learning.

\section{Confidence development}

The project facilitated young people's confidence in their ideas and self-expression. This resonates with the development of self-esteem. Participants constructed their understanding of their realities, eventually reaching a point where they felt able to voluntarily contribute to debates. There was a strong focus on this self-development throughout, with many expressing a boost in confidence, self-reflection and personal change: 'It's been good for confidence being around so many different people, I can talk to anyone now, it's literally second nature' (Paul).

This included confidence to talk to others, write lyrics, record tracks and produce music. Having a place to voice opinions and being listened to was recognized as a key benefit of the project, even for those who had previously felt anxious about group interaction:

I suffer from social anxiety and coming here I feel more comfortable talking out here - it's a good environment. That is helping my social anxiety stuff. It feels safe. In a small group where I can be like open and say stuff. (Sarah)

Personal change was attributed to dialogue with others, listening to their stories and critically reflecting on their own experiences:

It's the best way to change yourself, express yourself and before [the project] I thought I honestly had the roughest ride going but now I don't feel like I'm the only one that's kind of gone through this hard stage in my life. (Peter)

Self-confidence in terms of feeling 'safe to speak out' (Andrew) and feeling 'comfortable in the group' (Oliver) were important outcomes, identifying the self as a positive agent for change as confidence developed. This meant that facilitators also had to balance the security of speaking out in the group with 'challenging' their assumptions. This was managed through drawing on different people's experiences and presenting different perspectives, for instance from other contexts. In this way, participants developed not only confidence to speak their mind but also a willingness to consider alternative viewpoints.

\section{Skill development}

In addition to personal development, a series of transferrable skills were also fostered. Participants managed website content, argued coherently, wrote film and album reviews, expressed ideas and listened to others, conducted interviews, resolved conflict, developed lyric writing and singing and engaged with multimedia technologies. Some participants claimed to have developed new communication skills that they intended 
to apply in interview and employment situations. The social aspect of the project enabled social skill development: 'I've definitely made a few new friends and people I can work with on some music stuff. It's good connections' (Matt).

Many developed transferrable skills in media and music. They discovered new music, learned how to engineer sound, began critiquing existing messages that hiphop music conveyed and developed new initiatives for music projects. They had developed lyric writing skills and widened their musical understanding, including reviewing albums and posting the reviews online. This gave the young people an opportunity to write about something that interested them and improve their literacy, learning about different types of music and engaging with it in new ways: 'We are free to do activities here and creative stuff. I recently made a beat, I can also make lyrics and spit messages' (Samantha).

For some, music did not previously feature heavily in their lives, but afterwards it informed their career aspirations. They also felt that having these opportunities gave them more ideas about what they would like to learn about or do. A peer mentor observed that: 'They learn a lot in terms of media stuff ... I ask "What would you like to learn?" and they say like "sound engineering" ... whereas a few months ago they' $\mathrm{d}$ be like, "oh I don't know". There's so much stimulus' (Reece).

For many the opportunity to develop these skills meant that they had been able to access further education and employment directly, had opportunities to broaden their networks and get involved with other activities and organizations. For some it had acted as a springboard for volunteering and work-experience opportunities. The project was heavily grounded in music, yet potential aspirations were not limited to music, with many hoping to pursue a youth work vocation, based on their positive experiences. This was facilitated through the integration of peer mentorship roles for long-term participants, and maintaining a positive working environment, providing skills and experience needed to achieve aspirations.

\section{Positive attitudes, personal development and peer support}

Key aims of the project were to reach marginalized youth and create a stronger sense of community. It was intended that this would include personal changes for the young people in terms of positive attitudes, self-confidence and transferable skills, enabling them to become role models for a wider community of marginalized young people, and increasing youth involvement in community development initiatives. The connectchallenge-change approach worked to integrate global issues with the perceptions and daily interactions of the young people's lives. Where existing literature considers these participants as 'alienated' and 'disenfranchised' (Halas, 2002; Riley and RustiqueForrester, 2002), there is the implication that they are separate from the rest of society. This project aimed to draw on participants' own experiences of exclusion and challenge power structures by resisting mainstream images. It used critical dialogue to demonstrate to participants that they were a valued part of society by legitimizing their habitus (Bourdieu, 1990) and encouraging them to connect with the wider community.

There was evidence that the experience was positive in terms of attitudes to learning and self-confidence, with participants citing peer relationships, enjoyment and positive attitudes, confidence and skill development as key. The space provided an environment in which no one was judging them or putting them down. Some participants got a better grasp of political ideas and expressed strong views about structural injustice and political systems, demonstrating a critical view of capitalism 
for example. As Peter commented, 'the system is designed to benefit the rich, and it's the people with power that control who has access to what'. The project did not necessarily lead to political engagement in the case of all participants.

However, there was a greater awareness of injustice at a range of levels in most of the participants interviewed, demonstrating a first step to overcoming oppression (McLaren, 2009; Brookfield, 2000). This was coded as taking empowering action and developing consciousness. The extent to which the global dimension of the issues was highlighted within the sessions varied. Some participants demonstrated an increased understanding of and reflection on social issues, recognizing both the local and the global dimension.

One key benefit was having a place where they had access to facilities they valued, and a safe space to get together and pursue common aims. Engagement can be enhanced by the perception of spaces as 'safe' or 'comfortable' by young people (Whitlock, 2007). There was an element that allowed for discussing routes to positive change, but this was not pushed onto the young people. Again, this demonstrates how the intended outcomes were balanced with a participant-led pedagogy; a range of possible routes to change were highlighted but participants were also free to engage in their own ways, making the learning potentially more transformative (Mezirow, 2000; Brown, 2014).

The environment was one in which they could escape pressures they faced elsewhere and feel safe being exposed to multiple perspectives. Considering Adams' (2010) principles of good global youth work, this project demonstrated that hip-hop has the potential to engage young people in a critical analysis of local and global influences on their lives and communities, and raise awareness of globalization and diversity, particularly in relation to issues of justice and equality.

There is evidence of these young people engaging in peer support with the wider community. Some mentored other groups, such as community organizations, charities, Brownies and Guides, and theatre groups. Others reported talking about the issues raised, or showing tracks they had made, to family and friends, which stimulated further conversation on the issues. In addition, the young people felt proud of how they had reached out to more peers through the creative outputs online, demonstrating the outcome of dissemination. This enhanced their self-esteem, as they felt able to pass the learning onto others to enact further action on injustice (Brown, 2018).

It is difficult to quantify the impact of the project on these outcomes, precisely because of the informal nature of the project. Some engaged sporadically, others had attended previous projects run by the organization; most had complex work and home lives that make it difficult to entirely attribute any of these outcomes exclusively to the project, or to track progress of particular participants through the three years of the project. Indeed, it is difficult to give a clear background of each of the participants in terms of their 'marginalized' status. We did not collect data on NEET status or other proxies for marginalization. Nevertheless, by drawing on the views of the participants and eliciting their perceptions of the outcomes they achieved, and mapping these against the project aims and theoretical framework, we suggest that this format was beneficial and would be worth replicating.

\section{Making positive change through hip-hop}

The findings suggest that opening informal spaces of this nature, with a medium of creative experiential learning such as hip-hop, can have positive outcomes for young people and facilitate engagement with pro-social behaviours and social 
issues. Participants discussed finding their own voice. The project space enabled collaboration through dialogue without fear of ridicule or dismissal. This value on youth voice was crucial, and the combination of hip-hop with the connect-challenge-change methodology, facilitated confidence and skill development. This approach engaged them not as consumers of hip-hop messages but creators of their own discourse. As with Dedman (2011), we found that participation in creative interactions with hip-hop provided more opportunities for critical thinking and empowerment than the 'banking education' (Freire, 1972) of passive consumption.

The project engaged young people embodying a habitus that left them feeling excluded from mainstream education, and therefore more likely to buy into discourses that place them 'at risk' of disengaging further. By using a common language, global youth work through hip-hop demonstrates an innovative approach to reaching communities disconnected from formal education. The informal community valued their skills and legitimized their knowledges, allowing them to develop confidence and self-esteem, which in turn helped them to become more positive about learning. They were able to support each other and, through their passion for the issues they raised, also reach a wider community of young people to give voice to messages of sustainable and positive change. This data demonstrates that hip-hop provided a useful vehicle for connecting young people to global social issues. It provides a useful 'hook' to engage young people, although it is only one aspect of the culture. Other forms of creative expression, such as graffiti, were used in the project and it is this creative dimension that provided this way of connecting young people. By combining this with the connect-challenge-change methodology and facilitating discussion on specific issues that the young people related to, participants developed a critical awareness of social realities and were empowered to feel they had the capacity to affect change. This case study will be of interest to organizations and funders seeking to equip 'marginalized' young people with positive attitudes to learning, skills and confidence development, thus encouraging pro-social behaviours.

\section{Notes on the contributors}

Laura Louise Nicklin is an early career researcher from the Department of Education at the University of York, based in the Centre for Research in Education and Social Justice. She engages in research with both adults and young people and is currently finishing her PhD investigating theatre-focused prison-based criminal rehabilitation projects. Her most recent research was conducted in the US prison context using ethnographic research methods. Her primary research interests are education and social justice, artsbased educational research, alternative education and criminal rehabilitation.

Eleanor J. Brown is Senior Lecturer at the University of York, based in the Centre for Research in Education and Social Justice. Eleanor previously worked as a qualitative researcher at the University of Nottingham and has worked with a variety of NGOs in the UK, Spain, Costa Rica, Guatemala and Cambodia. Her primary research interests are in international development and global citizenship education, social justice, and critical thinking. She has undertaken research in both formal and non-formal educational settings with adults and young people.

\section{References}

Abrams, N.D. (1995) 'Antonio's B-Boys: Rap, rappers, and Gramsci's intellectuals'. Popular Music and Society, 19 (4), 1-19. 
Adams, P. (2010) A History of Global Youth Work (DEA Thinkpiece). London: Think Global.

Adams, T.M. and Fuller, D.B. (2006) 'The words have changed but the ideology remains the same: Misogynistic lyrics in rap music'. Journal of Black Studies, 36 (6), 938-57.

Baker, F. and Bor, W. (2008) 'Can music preference indicate mental health status in young people?'. Australasian Psychiatry, 16 (4), 284-8.

Baker, S. and Homan, S. (2007) 'Rap, recidivism and the creative self: A popular music programme for young offenders in detention'. Journal of Youth Studies, 10 (4), 459-76.

Batsleer, J.R. (2008) Informal Learning in Youth Work. London: SAGE Publications.

Berger, K.S. (2003) The Developing Person through Childhood and Adolescence. 6th ed. New York: Worth Publishers.

Bourdieu, P. (1990) The Logic of Practice. Trans. Nice, R. Stanford: Stanford University Press.

Brookfield, S.D. (2000) 'Transformative learning as ideology critique'. In Mezirow, J. and Associates Learning as Transformation: Critical perspectives on a theory in progress. San Francisco: JosseyBass, 125-48.

Brown, E.J. (2014) 'Fair-minded critical thinking in development education: Reflections on pedagogies for transformation'. International Journal of Development Education and Global Learning, 6 (1), 5-25.

Brown, E.J. (2018) 'Practitioner perspectives on learning for social change through non-formal global citizenship education'. Education, Citizenship and Social Justice, 13 (1), 81-97.

Bryman, A. (2016) Social Research Methods. 5th ed. Oxford: Oxford University Press.

Calkins, S.D. and Keane, S.P. (2009) 'Developmental origins of early antisocial behavior'. Development and Psychopathology, 21 (4), 1095-109.

Campbell, P.S., Connell, C. and Beegle, A. (2007) 'Adolescents' expressed meanings of music in and out of school'. Journal of Research in Music Education, 55 (3), 220-36.

Cieslik, M. and Pollock, G. (eds) (2002) Young People in Risk Society: The restructuring of youth identities and transitions in late modernity. Aldershot: Ashgate Publishing.

Darder, A., Baltodano, M.P. and Torres, R.D. (2009) 'Critical pedagogy: An introduction'. In Darder, A., Baltodano, M.P. and Torres, R.D. (eds) The Critical Pedagogy Reader. 2nd ed. New York: Routledge, 1-20.

Dedman, T. (2011) 'Agency in UK hip-hop and grime youth subcultures - peripherals and purists'. Journal of Youth Studies, 14 (5), 507-22.

Eyerman, R. (2002) 'Music in movement: Cultural politics and old and new social movements'. Qualitative Sociology, 25 (3), 443-58.

Forman, M. (2013) 'Hood work: Hip-hop, youth advocacy, and model citizenry'. Communication, Culture and Critique, 6 (2), 244-57.

Freire, P. (1972) Pedagogy of the Oppressed. Trans. Ramos, M.B. New York: Continuum.

Giddens, A. (1991) Modernity and Self-Identity: Self and society in the late modern age. Stanford: Stanford University Press.

Goodman, R. (1999) 'The extended version of the Strengths and Difficulties Questionnaire as a guide to child psychiatric caseness and consequent burden'. Journal of Child Psychology and Psychiatry, 40 (5), 791-9.

Gracyk, T. (2001) I Wanna Be Me: Rock music and the politics of identity. Philadelphia: Temple University Press.

Halas, J. (2001) 'Playtime at the treatment center: How physical activity helps troubled youth'. Avante, 7 (2), 1-13.

Halas, J. (2002) 'Engaging alienated youth in physical education: An alternative program with lessons for the traditional class'. Journal of Teaching in Physical Education, 21 (3), 267-86.

Hanrahan, F. (2014) 'Youth Disaffection: An interplay of social environment, motivation, and selfconstruals'. Unpublished PhD thesis, University of Sussex.

Hara, A.F. (2012) 'RAP (requisite, ally, protector) and the desperate contemporary adolescent'. In Hadley, S. and Yancy, G. (eds) Therapeutic Uses of Rap and Hip-Hop. New York: Routledge, 3-26.

Herd, D. (2014) 'Changes in the prevalence of alcohol in rap music lyrics 1979-2009'. Substance Use and Misuse, 49 (3), 333-42.

Hollander, J. and Quinn, J. (2016) 'More than noise: Employing hip-hop music to inform community development practice'. Community Development, 47 (5), 652-69.

Holroyd, R.A. and Armour, K.M. (2003) 'Re-engaging disaffected youth through physical activity programs'. Paper presented at the British Educational Research Association (BERA) Annual Conference, Heriot-Watt University, Edinburgh, 11-13 September 2003.

Hunnicutt, G. and Andrews, K.H. (2009) 'Tragic narratives in popular culture: Depictions of homicide in rap music'. Sociological Forum, 24 (3), 611-30. 
Illich, I. (1973) Deschooling Society. Harmondsworth: Penguin.

Keyes, C.L. (2004) Rap Music and Street Consciousness. Urbana: University of Illinois Press.

Kitwana, B. (2002) The Hip Hop Generation: Young blacks and the crisis in African American culture. New York: Basic Civitas Books.

Kubrin, C.E. (2005) 'Gangstas, thugs, and hustlas: Identity and the code of the street in rap music'. Social Problems, 52 (3), 360-78.

Marsh, H.W. (1990) 'Causal ordering of academic self-concept and academic achievement: A multiwave, longitudinal panel analysis'. Journal of Educational Psychology, 82 (4), 646-56.

Martinek, T.J. and Hellison, D.R. (1997) 'Fostering resiliency in underserved youth through physical activity'. Quest, 49 (1), 34-49.

McDonnell, J. (1992) 'Rap music: Its role as an agent of change'. Popular Music and Society, 16 (3), 89-107.

McLaren, P. (2009) 'Critical pedagogy: A look at the major concepts'. In Darder, A., Baltodano, M.P. and Torres, R.D. (eds) The Critical Pedagogy Reader. 2nd ed. New York: Routledge, 61-83.

Mezirow, J. (2000) 'Learning to think like an adult: Core concepts of transformation theory'. In Mezirow, J. and Associates Learning as Transformation: Critical perspectives on a theory in progress. San Francisco: Jossey-Bass, 3-34.

Miranda, D. and Claes, M. (2004) 'Rap music genres and deviant behaviors in French-Canadian adolescents'. Journal of Youth and Adolescence, 33 (2), 113-22.

Nash, P. and Henderson, L. (2010) 'Work in progress: Facilitating transition for vulnerable learners moving to secondary school'. Psychology of Education Review, 34 (2), 39-42.

Newburn, T., Shiner, M. and Young, T. (2013) Dealing with Disaffection. London: Routledge.

Orth, U. and Robins, R.W. (2014) 'The development of self-esteem'. Current Directions in Psychological Science, 23 (5), 381-7.

Potter, R.A. (1995) Spectacular Vernaculars: Hip-hop and the politics of postmodernism. Albany: State University of New York Press.

Riley, K.A. and Rustique-Forrester, E. (2002) Working with Disaffected Students: Why students lose interest in school and what we can do about it. London: Paul Chapman Publishing.

Schwartz, K.D. and Fouts, G.T. (2003) 'Music preferences, personality style, and developmental issues of adolescents'. Journal of Youth and Adolescence, 32 (3), 205-13.

Shah, H. (2010) 'Foreword'. In Williams, S. and Edleston, J. (eds) Connect, Challenge, Change: A practical guide to global youth work. London: DEA, 2-3.

Smith, E.R. and Mackie, D.M. (2007) Social Psychology. 3rd ed. New York: Psychology Press.

Stapleton, K.R. (1998) 'From the margins to mainstream: The political power of hip-hop'. Media, Culture and Society, 20 (2), 219-34.

Steer, R. (2000) A Background to Youth Disaffection: A review of literature and evaluation findings from work with young people. London: Community Development Foundation.

Sugden, J. and Yiannakis, A. (1982) 'Sport and juvenile delinquency: A theoretical base'. Journal of Sport and Social Issues, 6 (1), 22-30.

Travis, R. and Bowman, S.W. (2012) 'Ethnic identity, self-esteem and variability in perceptions of rap music's empowering and risky influences'. Journal of Youth Studies, 15 (4), 455-78.

Tyson, E.H. (2002) 'Hip hop therapy: An exploratory study of a rap music intervention with at-risk and delinquent youth'. Journal of Poetry Therapy, 15 (3), 131-44.

Wellington, J. (2015) Educational Research: Contemporary issues and practical approaches. 2nd ed. London: Bloomsbury Academic.

Whitlock, J. (2007) 'The role of adults, public space, and power in adolescent community connectedness'. Journal of Community Psychology, 35 (4), 499-518.

Williams, S. and Edleston, J. (eds) (2010) Connect, Challenge, Change: A practical guide to global youth work. London: DEA. 